\title{
A Contrastive Study of Cultural Diversity of Learning Styles \\ between China and the United States
}

\author{
Hong Jian \\ Language and Literature Department \\ Xishuangbanna Vocational \& Technical Institute \\ Jinghong 666100, China \\ Tel: 86-691-662-0089 E-mail: ruthy123@126.com
}

\begin{abstract}
This paper makes a contrastive study of learning styles between China and the U.S. from five aspects and recognizes that the differences are due to the influence of cultural diversity such as individualism and collectivism, Confucianism, utilitarianism and pragmatism etc.
\end{abstract}

Keywords: Learning styles, Cultural diversity, Differences, Influence

\section{Introduction}

How we learn is influenced by culture. As cultures are different, it's natural to expect differences in the styles of learning in different countries. According to Bennet's (1996) definition, "A learning style is a particular way that an individual receives and processes information." Another definition is cited from the paper "knowing and learning" in a book called Interpreting Cultural Differences (Mclaren, 1998: 158), "Learning style is the way in which human beings concentrate on, absorb, process and retain new and difficult information." What's more, most people learn in a variety of ways. The most common ways for any individual will depend on the culture. So here the writer will make a contrastive study of the cultural diversity of learning styles between China and the U.S. respectively.

\section{A Contrastive study of learning styles between China and the U.S.}

\section{1 'Field-dependent'v.s 'field-independent'}

Chinese culture as a high-context, traditional, collectivistic society is field-dependent. In such culture any interaction resulting in discord means one or all lose 'face', so individuals have a more global perspective their surroundings; they are more dependent to the social field. That is why Chinese students prefer to work with others, seek guidance from the teacher, and receive rewards based on group relations. In contrast, the United States as a low-context, highly industrialized, individualistic society is predominantly field-independent, the students in it "tend to more analytical and more comfortably focus on impersonal, abstract aspects of stimuli in the environment (Gollnik \& Chinn, 1994)". So the students in the U.S. prefer to work independently, are task oriented, and prefer rewards based on individual competition.

\subsection{Teacher-centered v.s. students-centered}

In Chinese classroom teaching should be clearly structured, and information-packed. Some of students even consider discussion as a waste of precious time that ought to be used by the teacher to deliver intellectual treasures to the students. It's a typical teacher-oriented mode. The teacher mostly dominates the class and generalizes the key points of the content according to the concrete curriculum standards and requirements of examinations related to specific fields and levels of the students. By contrast, In American classrooms, experiential learning, problem solving, case studies, and participatory teaching methods are practiced. "Students learn how to solve problems and reach conclusion by trail and error. They practice over and over, expecting and accepting mistakes, until they become skilled"(cited in Di,2002:181). In the university, a typical strategy of American teachers is to lecture on some aspects of their course subject but expect other aspects to be covered by the assigned readings. Chinese students are not used to this kind of assignment.

\subsection{Indirect communication v.s. direct communication}

Culture influences the degree to which communication in the classroom is direct or indirect. Chinese willingly accept the role of the attentive listeners, the students are not used to making comments or asking questions in class. They won't volunteer when they obviously know the answer. It's very common for them to keep quiet and never ask the teacher questions in class, let alone interrupt with an opinion, but as soon as the class ends, they will cluster the teacher's desk 
to ask their questions one after one. They would also offer their suggestions about the lesson at this time. Whereas, American students usually enjoy the act of speaking and assume the role of the speakers. The teachers generally hope to encourage informal discussions and debates in their classes. Furthermore, critical thinking, judgmental questioning, and active initiation of discussion are expected from students in the American school system. Independence and participatory learning is much more encouraged in classes.

"The uneasiness that Chinese often experience in public speaking not only is due to a lack of training and practice but also is a result of heightened concern for relational outcomes" (Gao \& Ting-Toomey, 1998:83). In ancient China, The Analects of Confucius give us the first two approved attitudes for students' submission to authority-parents, elders and superiors and submission to the mores of society. One of the famous saying of Confucius is "Let the emperor be an emperor, the subject a subject, the father a father, and the son a son." The basic rule is "Honor the hierarchy first, your vision for truth second". The superior must always be accorded face, so one first agrees with what he or (occasionally) she has said. Only then is difference voiced, if possible through a third party, and in private"( cited in Mclaren,1998:166).

\subsection{Theory-oriented v.s. problem-oriented}

In China, the transmission of knowledge is oriented more toward theory than toward practice or application, so memorization of details and facts is important. As Chinese students in a conformist educational system, they are happier with memorizing and reproducing information than with problem-oriented and more active teaching strategies. They expect lecturers to teach them everything they expected to know. They have little desire to discover for themselves. In contrast, in the United States, the emphasis is on knowing where to finds facts and how to use them creatively. Teachers reward those who ask questions.

\subsection{Synthetic thinking v.s. analytical thinking}

It is said that Chinese students more often employ synthetic thinking patterns. They tend to synthesize elements into a unit, with the emphasis on the "whole". In addition, "Stewart (cited in Hu, 2004:464) notices that the Chinese do not analyze a topic divisively by breaking it down into parts and their thinking is based upon concrete conceptions weighted with judgment and lacking the precision and abstraction of Western concept." He concludes, "The Chinese are more likely to think by means of analogies and to make greater use of metaphors and similes. In contrast, Americans' view is that knowledge, a product of thought, is an understanding of cause and effect, the result of thought which is linear, logical and analytic. "They tend to analyze and dissect things into elements in order to understand them properly. Their emphasis is upon the parts rather than upon the whole of things" (Zhang, 2003:77).

\section{Recognizing the influence of cultural diversity}

\subsection{The influence of collectivism and individualism}

Chinese culture is believed to be collectivism-oriented where the basic unit of the society is the family (collective), not the individual. Each person is part of a group; children learn to think in terms of "we", so it sometimes referred to as a collective or "we" culture (Zhang, 2003:53-54). Off all the American value, individualism is probably the most basic. Benjanmin Frankinlin epitomized early American individualism in his writings and suggested "God helps those who help themselves" (cited in Di, 2002:78). In individualist cultures, from birth onwards, children are encouraged to have wants and views of their own and to express them. If they disagree with parents or teachers they say so and from the disagreement a solution is reached. Because children learn to think in terms of "I", some people refer to the American culture as "I" culture, as individuals are emphasized.

A significant difference exists in educational situations in individualist and collectivist cultures. The pursuit of individual rights and interests is considered utterly legitimate. Self-actualization and the maximal realization of individual potential are supreme aims in life. Collectivistic cultures, in contrast, require that individuals fit into the group. A key belief of people in collectivistic cultures is that the smallest unit of survival is the collective .In many situations people in collectivist cultures have internalized the norms of their collectives so completely that there is no such things as a condition between group goals and personal goals. The children in collectivist homes and schools are expected to take their opinions from others, and to go along with what is best for the other reward for excellence goes to the group and responsibility for performance is owned to the group. Even the choice of study and occupation is a group decision rather than a personal one. Interdependence is always important and go-between is relied upon. The relationship matters more than success.

\subsection{The influence of the educational system}

Most cultures that have formed educational systems teach much the same content, but educational differences can be found in what a culture emphasizes and how the content is taught. In Chinese educational objectives, political-functional orientation is prominent. At present, because the education system is exam-oriented the exam results play a key role in evaluating the academic achievements for students. People over-emphasize the students' scores 
ignoring "learning by doing" and over-emphasize theory rather practice. Now China has acknowledged that quality-oriented education is a universal purpose of education and is undertaking a transformation to the proper ways for the younger generation.

The American educational system is based on the idea that as many people as possible should have access to as much education as possible. Free public schools supported by taxes were established in the early days of the $20^{\text {th }}$ century, with each state responsible for organizing its own educational system. All American states have compulsory attendance laws that require young to attend school until a specified age from 16-18. Generally speaking, the goal of American educational system is to teach children how to learn and to help them reach their maximum potential.

\subsection{The influence of the Confucianism}

Confucius was one of the greatest philosophers and educators in ancient China and his philosophy has been called Confucianism. "Humanity" is the core of the Confucianism which had great influence on Chinese society one generation after another. "The whole of his educational process aimed at the production of the way-a mode of life which reflects and expresses the virtue and harmony that humanity is the natural moral of man. It's the nature character of man, without this quality, a man is not a real man. So he taught people to love each other, to help each other, then to behave properly. These contain the secrets of a harmonious and peaceful state” (Hu, 2006:284). As an educator, Confucius had summarized much precious educational experience from long-year teaching career, such as "insatiable desire to learn, tireless in teaching", "setting a good example for students", "teaching without distinction", "Reading without thinking results in bewilder man; thinking without reading results in peril", "Knowing something is not as good as liking something, liking something is not as good as taking pleasure in something" and so on. These teaching ideas of Confucius play a significant role in guiding out teaching nowadays. Chinese proverb "Give a man a fish and you feed him for a day. Teach a man to fish and you feed him for a lifetime" shows us the significance of the Confucius' enlightening reflection.

\subsection{The influence of the utilitarianism and pragmatism}

The Americans; definition of success is largely one of acquiring wealth and a high material standard of living. Therefore, Americans have valued education for its monetary value. On the other hand, in helping to educate a student for adult work and adult life American schools strive, above all, to be practical. "John Dewey's philosophy, which states that the only worthwhile knowledge is knowledge that can be used, has a great effect on American educators. They don't want to teach useless facts which will quickly be forgotten; they want to teach attitudes and skills which will help produce useful, responsible, happy adults."(Luo, 1997:98) Dewey also influenced teaching techniques. He believed "Education is life" and stressed, "children as educational enter" Education must be meaningful and children learn best by doing, thus science is taught largely through student experimentation.

\section{Conclusion}

As famous saying goes like that "Every coin has two sides". Cross (cited in Mclaren, 1998:172), in discussing individual differences rather than cultural differences, plainly states," No particular learning style is in itself superior to another". Due to cultural diversity, Americans evaluate individualist culture and emphasizes the pragmatism of the knowledge, but to some extent, the result of teaching and learning styles lead to lack of systematical knowledge, In contrast, owing to the deep-rooted influence of Confucianism for thousands of years. Harmony, unity, and hierarchy are important considerations for Chinese students in the process of learning. Its teaching put more emphasis on transmission of systematical knowledge, ignoring the cultivation of creativity and innovation.

As we all know "Rome wasn't built in a day". Actually, in China we have taken some treasures to promote teaching methods and strategies in teaching reforms and have made some progress in them. The teachers are feeling their ways to carry out the essence of the qualified-oriented education in China. They are trying to transfer from teacher-centered mode to students-centered mode in teaching process. They should positively guide their students in choosing appropriate learning styles. Moreover, since "All roads lead to Rome", we can't follow suit totally and the reforms of learning styles in China can be carried out in the improving educational system by learning strong points from others but rejecting their weakness and integrate both academic and practice for children.

\section{References}

Bennet, Milton J. (1986). “Towards Ethno-relativism: A Developmental Model for Intercultural Sensitivity.” In Cross Cultural Orientation: New Conceptualizations and Application, edited by R. Michael.Lanham, MD: University Press of America.

Di, Y.H. (2002). American Culture. Jilin Science \& Technology Press. pp166-183.

Gao, G. and Ting-Toomey, S. (1998). Communicating effectively with the Chinese. SAGE Publications. pp69-85.

Gollnik, D.M and Chinn, P.C.. (1994). Multicultural Education in a Pluralistic Society. New York: Macmillan. 
$\mathrm{Hu}$, D.Y. (2004). The Implications of Individualist and Collectivist Perception China's EFLT. International Journal of Diversity in organizations, Communities and Nations, 4: 464.

Hu, D.Y. ( 2006). Tracking Some Educational Issues of China and the United States. In Hu, D.Y.(Eds.), the Exploration of Modern Teaching Theories and Methods in China's EFLT. Yunnan National Press .p284.

Luo, X.M. (1997). Images of British and American Culture and Society. Central China Science \&Technology University Press.

McLaren, M. (1998). Interpreting Cultural differences, London, Peter Francis Publisher. pp158-183.

Zhang , A.L. (2003). Intercultural Communication. Chongqing University Press. 